NEWS ANALYSIS

\section{Covid-19: Concerns persist about purpose, ethics, and effect of rapid testing in Liverpool}

\author{
The government is hailing Liverpool's testing pilot as a great success and plans to offer rapid lateral \\ flow tests to other areas with high rates of covid-19. But the scheme raises more questions than \\ answers, finds Jacqui Wise
}

Jacqui Wise

Liverpool started its community testing pilot on 6 November, with all residents and workers offered repeat covid-19 testing, even if they have no covid symptoms, "to find more positive cases and break chains of transmission." Whether the scheme has indeed contributed substantially to a fall in infection rates remains uncertain, and it has been criticised over the lack of transparency, the accuracy of the tests being used, and costs and potential harms. ${ }^{12}$

On 26 November it was announced that Liverpool would move out of the toughest tier 3 restrictions and into tier 2 once the national lockdown ends on 2 December. The prime minister, Boris Johnson, and England's health secretary, Matt Hancock, both claimed that this was down to the success of the testing pilot, and they urged other tier 3 areas to use lateral flow tests to drive down infection rates.

"But we haven't learnt anything from Liverpool, as nothing has been put in the public domain," said Jon Deeks, professor of biostatistics at Birmingham University and leader of Cochrane's covid-19 test evaluation activities. "We only know the number of positive tests, and we don't know the number of false positives or false negatives.” Deeks is particularly concerned about the sensitivity of the Innova lateral flow test, which can be as low as 58\% when used by the public, meaning that as many as half of cases will be missed. " "Statements that these cases do not matter as they will not be infectious are not based on evidence. Infectious cases will be missed, and we need to know how many," he said.

\section{What was the purpose of the testing?}

There has been confusion over the purpose of the testing in Liverpool and whether it is, in fact, screening. At first the term mass testing was widely used by the government and on Liverpool City Council's website, although the scheme is now more often referred to as community testing.

Allyson Pollock, director of the Newcastle University Centre for Excellence in Regulatory Science, is among experts who have been calling for clarity about the purpose of the testing. ${ }^{4}$ She said that what is happening is population screening of asymptomatic people, which is not endorsed by the World Health Organization or the government's SAGE committee. "There is very little evidence on asymptomatic transmission. And testing asymptomatic people is likely to be of only marginal benefit”
She added, "The whole thing seems extraordinarily rushed and poorly thought through. It appears they are making it up as they go along, and they have marginalised experts who could have offered help, such as the National Screening Committee.”

However, Iain Buchan, dean of the Institute of Population Health at the University of Liverpool, who is one of the senior clinicians involved in analysing the data, said the pilot scheme has been misrepresented. "The city was clear with the government from the start that we sought community open access testing to underpin a targeted approach and not untargeted mass testing," he told The BMJ. He says that what the scheme is doing is not screening but an urgent public health intervention.

Buchan said that Liverpool was pursuing "SMART" testing: systematic, meaningful asymptomatic repeated testing. This has three components: test to protect (where testing is accessible to the whole community but can focus on people at highest risk, such as care home visitors), test to release (to enable people to exit quarantine earlier), and test to enable (to allow a return to activities).

Buchan said they were just completing the pilot's first phase, which was about making testing accessible to all members of the community. They are about to enter phase 2, which is about targeting areas of high need, such as care home visiting, and release from lockdown.

\section{Lack of transparency}

Much of the criticism has focused on the general lack of information about the pilot. "Why haven't they published their protocol, what information sheets were given to the public, and was proper informed consent obtained?" Pollock asked. "They have torn up the rule book on research governance and ethics."

In response, Buchan said that they have evaluation plans for each sub-project, shared with the Department of Health and Social Care and reviewed weekly. He points out that academic input was requested for service evaluation and not for research but that researchers have sought ethical approvals for fieldwork. He notes that economic evaluation was less relevant, because test kits had already been purchased and his team was carrying out “after-action research"-evaluating a complex heath intervention. Live dashboards are updated every 30 
minutes and emailed in reports twice daily. Public reports will be made soon.

\section{Has the testing reduced covid in Liverpool?}

There is no doubt that the prevalence of covid-19 has come down rapidly, from almost 700 per 100 ooo population in mid-October to 137.7 per 100 ooo on 26 November. However, Liverpool was the first area to go into tier 3 restrictions on 14 October. “Boris Johnson's claim that rates are coming down in Liverpool due to the testing is not good science," said Deeks. "Liverpool was ahead of other areas of the country on their wave, and their figures had already started to come down."

The latest figures show that between 6 and 26 November 108304 people in Liverpool were tested with lateral flow tests and that 703 tested positive. In the same period 65050 were tested with PCR tests, of whom 2158 tested positive. But Pollock points out that it is impossible to know the true picture because we don't know whether people going for the lateral flow tests were truly asymptomatic or were pre-symptomatic, or did have symptoms and just wanted a quick test. Another unknown is how many of those testing positive on the lateral flow test actually went on to have a confirmatory PCR test.

\section{Is testing reaching those most at risk?}

An advocate of mass testing, Julian Peto, professor of epidemiology at the London School of Hygiene and Tropical Medicine, told The $B M J$, "The pilot scheme in Liverpool has been ridiculous and an absurd way to go about mass testing. It's missing those in the areas that are most affected.” He added, “They have been inundated with the worried well, and those in the most deprived areas are not coming forward."

A report on BBC's Newsnight programme on 23 November said that the testing pilot was failing to reach the poorest communities in the city and that in some parts only $4 \%$ of residents had turned up to be tested. ${ }^{5}$ But Buchan dismissed the $4 \%$ figure as "unfounded." He said, "Uptake of lateral flow testing has been much higher than PCR testing in deprived areas, and more so as test site deployments were adapted to the signals from the data."

\section{Potential harms}

Pollock believes that the harms of testing have not been adequately considered. "Some people are getting false reassurance as the tests are not very accurate," she said. "People were being told on the radio that if they got a negative test they could go about their business." She added that, since she raised concerns, the FAQ page on the Liverpool council website has been updated to include information on false negatives, and it now says that a negative lateral flow test result does not constitute a "green pass."

Another issue is the cost. It is not known how much has been spent on the pilot in Liverpool, which has involved 2000 army personnel. But the government recently advertised a contract for £912m to deliver rapid testing across the country. "This is costing huge amounts of money and resources," says Pollock. "It could have been better used for tracing contacts and supporting those who are isolating."

The government has said that local authorities in tier 3 "will be offered support from NHS Test and Trace and the armed forces to deliver a 6 week rapid community testing programme." But it is not clear how much support local areas would be given, and from 3 December there will be 23 million people under tier 3 restrictions.
Maggie Rae, president of the Faculty of Public Health, said that local areas would need much support. "We are going to be overwhelmed and will need to prioritise our actions and resources." She expressed the view that, with the promising news on vaccines, resources should be put into rolling out vaccination rather than mass testing.

Rae did welcome the government's announcement on 26 November that local authorities will be able to decide how to use the lateral

flow test kits. "We have been pushing for more local determination and more targeted testing, otherwise it has the potential to widen inequalities," she said.

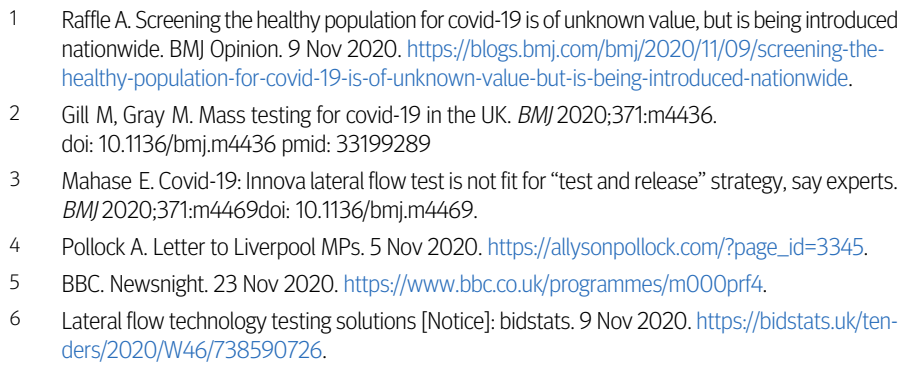
nationwide. BMJ Opinion. 9 Nov 2020. https://blogs.bmj.com/bmj/2020/11/09/screening-thehealthy-population-for-covid-19-is-of-unknown-value-but-is-being-introduced-nationwide.

2 Gill M, Gray M. Mass testing for covid-19 in the UK. BMJ2020;371:m4436. doi: 10.1136/bmj.m4436 pmid: 33199289

3 Mahase E. Covid-19: Innova lateral flow test is not fit for "test and release" strategy, say experts. BMJ 2020;371:m4469doi: 10.1136/bmj.m4469.

4 Pollock A. Letter to Liverpool MPs. 5 Nov 2020. https://allysonpollock.com/?page_id=3345.

$5 \quad$ BBC. Newsnight. 23 Nov 2020. https://www.bbc.co.uk/programmes/m000prf4.

6 Lateral flow technology testing solutions [Notice]: bidstats. 9 Nov 2020. https://bidstats.uk/tenders/2020/W46/738590726.

This article is made freely available for use in accordance with BMJ's website terms and conditions for the duration of the covid-19 pandemic or until otherwise determined by BMJ. You may use, download and print the article for any lawful, non-commercial purpose (including text and data mining) provided that all copyright notices and trade marks are retained. 